\begin{tabular}{|c|c|c|}
\hline \multirow{3}{*}{$\begin{array}{r}\text { Case Reports in } \\
\text { Gastroenterology }\end{array}$} & \multirow{2}{*}{\multicolumn{2}{|c|}{ Case Rep Gastroenterol 2016;10:787-792 }} \\
\hline & & \\
\hline & $\begin{array}{l}\text { DOI: } 10.1159 / 000453658 \\
\text { Publisnea onitne: January 5, } 2017\end{array}$ & $\begin{array}{l}\text { (c) } 2017 \text { The Author(s) } \\
\text { Published by S. Karger AG, Basel } \\
\text { www.karger.com/crg }\end{array}$ \\
\hline & \multicolumn{2}{|c|}{$\begin{array}{l}\text { This article is licensed under the Creative Commons Attribution-NonCommercial } 4.0 \\
\text { International License (CC BY-NC) (http://www.karger.com/Services/OpenAccessLicense). } \\
\text { Usage and distribution for commercial purposes requires written permission. }\end{array}$} \\
\hline
\end{tabular}

\title{
Migration of Surgical Clips into the Common Bile Duct after Laparoscopic Cholecystectomy
}

\author{
Krishn Kant Rawal \\ Department of Gastroenterology and Liver Disease, Milestone Hospital, Rajkot, India
}

\section{Keywords}

Laparoscopic cholecystectomy · Surgical clip migration · Common bile duct stone

\begin{abstract}
Laparoscopic cholecystectomy (LC) is currently the treatment of choice for symptomatic gallstones. Associated complications include bile duct injury, retained common bile duct (CBD) stones, and migration of surgical clips. Clip migration into the CBD can present with recurrent cholangitis over a period of time. Retained CBD stones can be another cause of recurrent cholangitis. A case of two surgical clips migrating into the common bile duct with few retained stones following $L C$ is reported here. The patient had repeated episodes of fever, pain at epigastrium, jaundice, and pruritus 3 months after LC. Liver function tests revealed features of obstructive jaundice. Ultrasonography of the abdomen showed dilated CBD with few stones. In view of acute cholangitis, an urgent endoscopic retrograde cholangiopancreatography was done, which demonstrated few filling defects and 2 linear metallic densities in the $\mathrm{CBD}$. A few retained stones along with 2 surgical clips were removed successfully from the CBD by endoscopic retrograde cholangiopancreatography after papillotomy using a Dormia basket. The patient improved dramatically following the procedure.




\section{Case Reports in Gastroenterology}

Case Rep Gastroenterol 2016;10:787-792 DOI: $10.1159 / 000453658$

c 2017 The Author(s). Published by S. Karger AG, Basel www.karger.com/crg

Rawal: Migration of Surgical Clips into the Common Bile Duct after Laparoscopic Cholecystectomy

\section{Introduction}

One of the commonest and costly of all digestive diseases is the gallstone disease. Gallstones are common, especially in the Western population. The prevalence of gallstones in the United States is approximately $6 \%$ in men and $9 \%$ in women. Older age, female sex, and obesity are a few risk factors for gallstones. Usually gallstones do not cause any symptoms throughout the lives of most of the people harbouring them. These stones are called incidental gallstones and they are identified when imaging studies are done for different reasons (e.g., evaluation of abdominal pain, pelvic disease, and abnormal liver function tests [LFT]). If the person becomes symptomatic due to stones, the condition is called gallstone disease. Uncomplicated gallstone disease refers to a state associated with biliary colic in the absence of any complications. Complications of the gallstone disease include acute cholecystitis, choledocholithiasis, and biliary pancreatitis.

While the majority of patients with incidental gallstones will not develop symptoms attributable to the gallstones, approximately $15-25 \%$ will become symptomatic during 10-15 years of follow-up, but their initial symptoms are typically not severe [1]. Patients who develop symptoms initially report biliary colic rather than symptoms associated with the complications of gallstone disease. Since the mortality rate related to incidental gallstone disease is remarkably lower than that associated with treatment, prophylactic cholecystectomy is not indicated in asymptomatic patients. Once symptoms develop, they tend to recur and thereby increasing the risk for the complications of the gallstone disease. Therefore, cholecystectomy must not be delayed after the development of biliary symptoms. Elective nonsurgical treatment of gallstones is advised in all symptomatic patients who are poor candidates for surgery.

Cholecystectomy remains the gold standard for the treatment of gallstone disease. Around 60,000 cholecystectomies were performed in the UK in 2015. An estimated 750,000 laparoscopic cholecystectomies (LC) are performed annually in the United States (approximately $90 \%$ of all cholecystectomies). The overall serious complication rate still remains higher than that seen in open cholecystectomy, despite increasing experience with the procedure over the last so many years [2]. Laparoscopy in the present time is done by 3-port, 4port, or single-port technique, though it may also be performed through an open upper right abdominal incision. As the laparoscopic approach does not require the cutting of the rectus abdominis muscle, it is associated with less postoperative pain and good cosmetic effect. A short hospital stay resulting in reduced days off work are additional advantages over open cholecystectomy. In an LC operation, the cystic duct is divided after applying metallic surgical clips over it. This procedure also has few inherent complications like others. Serious complications that occur with LC include bile leaks, bile duct injury, bleeding, and bowel injury at times.

One of the complications of cholecystectomy is the migration of surgical clips into the common bile duct (CBD), albeit very rare [3]. A retained CBD stone is another complication often missed before LC. CBD stones can be divided into primary and secondary types. Secondary stones, which are the commonest, form in the gallbladder and then migrate into the CBD. Primary stones forming de novo within the CBD are less frequently seen. Stasis plays an important role in the formation of bile duct stones and can be due to stricture or other causes of obstruction like foreign bodies. The migrated surgical clip could be one of the foreign bodies providing the nidus for the bile duct stones. Migration of surgical clips is a wellknown phenomenon ever since their use in surgery. But biliary stones resulting from the 
Rawal: Migration of Surgical Clips into the Common Bile Duct after Laparoscopic Cholecystectomy

migrated clips are rare. Migration of the surgical clip into the CBD as a cause of biliary stone was first recognised in 1979 after open cholecystectomy.

Both of these complications (migration of surgical clips and retained CBD stones) can be missed easily. Presenting symptoms of both of these complications could be acute or recurrent cholangitis over a variable period of time. The exact pathophysiological process of clip migration is far from known. Described here is a case with both of these complications. She presented with recurrent cholangitis 3 months after LC.

\section{Case Report}

A 38-year-old lady presented with repeated episodes of jaundice. Jaundice used to be mild and fluctuating in nature lasting for 5-6 days according to her history. She also had high-grade intermittent fever just preceding jaundice. Upper right quadrant abdominal pain lasting for less than $6 \mathrm{~h}$ accompanied the jaundice. Each episode was associated with mild pruritus all over the body. The patient complained of these recurrent symptoms for the last 4 weeks. She also developed nausea and vomiting for the past few days when she decided to seek medical attention. She had undergone LC for acute calculus cholecystitis 4 months ago. There was no past history of abdominal pain, fever, or jaundice before LC. Ultrasonography (USG) done just before LC showed non-dilated CBD with normal LFT. Clinical examination revealed dehydration and moderate icterus. She was found to have a temperature of $39.2^{\circ} \mathrm{C}$ with associated tachycardia (HR 130/min). Scars of previous LC were noticed on her abdomen. There was marked tenderness in the upper right abdomen. Laboratory indices were as follows: WBC 12,100/mL, ALT 112 U/L (normal up to 41), AST $169 \mathrm{U} / \mathrm{L}$ (normal up to 40), ALP $671 \mathrm{U} / \mathrm{L}$ (normal up to 130), and total bilirubin $9.6 \mathrm{mg} / \mathrm{dL}$ (normal up to 1.2). Serum amylase was $46 \mathrm{U} / \mathrm{L}$ (normal up to 96) and serum lipase was $28 \mathrm{U} / \mathrm{L}$ (normal up to 51). USG showed few distal CBD calculi with dilated biliary radicles. A diagnosis of choledocholithiasis with cholangitis was thus confirmed. The patient was put on intravenous fluids and antipyretics with analgesics. Broad-spectrum antibiotics were started immediately. An urgent endoscopic retrograde cholangiopancreatography (ERCP) was performed. Pus was seen exuding from the papilla. A small amount of contrast was injected in the CBD, which demonstrated multiple filling defects in the lower CBD with 2 linear metallic densities in one of the defects (Fig. 1). Wide papillotomy was done and a few stones, including the one encasing 2 metallic surgical clips, were removed by a Dormia basket (Fig. 2). Pain and fever disappeared after the procedure with progressive normalisation of LFT. The patient was discharged after 3 days of hospitalisation.

\section{Discussion}

The long-term incidence of CBD stones after cholecystectomy is about $10 \%$. Most of the stones form de novo, while a few can form due to direct complications of surgery. Suture materials or metallic clips can migrate into the CBD where they act as a nidus for stone formation [4]. The first case of surgical clip migration after LC was reported in 1992 [5]. In spite of the very large number of LC performed worldwide, less than 100 cases of surgical clip migration have been reported in the literature.

The median time of clip migration is usually 2 years, but it can vary from 11 days to 20 years, while the median number of migrated clip is 1 (range 1-6) [3]. The exact sequence of 
Rawal: Migration of Surgical Clips into the Common Bile Duct after Laparoscopic Cholecystectomy

events leading to clip migration is poorly understood. A possible initial event could be cystic duct stump necrosis. This can be due to pressure exerted from intra-abdominal organ movements, ischemia, or infective complications [6]. The clip migrates towards a path of low resistance (usually the CBD) [7]. The protruding clip in the CBD promotes stone formation. In due course of time, the whole clip eventually falls away into the CBD as the stone becomes larger in size. Clip migration causing duodenal ulcer or emboli has also been reported [8,9]. The clinical presentation of stones formed due to clip migration is similar to non-iatrogenic stones. The success rate of ERCP for managing these complications is close to 80\% [3]. Application of a minimum number of clips with proper placement away from the cystic duct and CBD junction or use of absorbable clips could probably prevent the incidence of clip migration.

This case also highlights another important issue of retained CBD stones after cholecystectomy because there were multiple stones in the CBD apart from the one formed over the migrated clips. Unexpected retained CBD stone after cholecystectomy is a rare but recognised complication with a reported incidence of about $0.5-2.3 \%[10,11]$. The frequency of asymptomatic CBD stones in those undergoing cholecystectomy is around $10 \%$ in the literature [12]. The routine screening methods, viz. abdominal USG and LFT, could still miss retained CBD stones in many cases, like the present one. Therefore, the use of on-table cholangiogram or intra-operative laparoscopic ultrasound to reduce the incidence of retained CBD stones could be the better option, but no conclusive evidence exists to date $[13,14]$.

\section{Conclusion}

Clip migration and retained CBD stones are very rare complications of LC. They should be considered in the differential diagnosis of recurrent cholangitis in post-cholecystectomy cases. The key to successful management is to suspect them early and treat accordingly.

\section{Statement of Ethics}

Informed consent was obtained from the patient prior to the publication of this study.

\section{Disclosure Statement}

The author has no competing interest to declare.

\section{References}

1 Shabanzadeh DM, Sørensen LT, Jørgensen T: A prediction rule for risk stratification of incidentally discovered gallstones: results from a large cohort study. Gastroenterology 2016;150:156-167.

-2 Khan MH, Howard TJ, Fogel EL, Sherman S, McHenry L, Watkins JL, Canal DF, Lehman GA: Frequency of biliary complications after laparoscopic cholecystectomy detected by ERCP: experience at a large tertiary referral center. Gastrointest Endosc 2007;65:247-252.

-3 Chong VH, Chong CF: Biliary complications secondary to post-cholecystectomy clip migration: a review of 69 cases. J Gastrointest Surg 2010;14:688-696.

4 Qiang L, Liang T, Xingyu W, Lingjun M, Xitai S, Jianxin Z: Bile duct stone formation around a prolene suture after cholangioenterostomy. Pak J Med Sci 2016;32:263-266. 


\section{Case Reports in \\ Gastroenterology}

\begin{tabular}{l|l}
\hline Case Rep Gastroenterol 2016;10:787-792 \\
\hline DOI: 10.1159/000453658 & $\begin{array}{l}\text { @ 2017 The Author(s). Published by S. Karger AG, Basel } \\
\text { www.karger.com/crg }\end{array}$ \\
\hline
\end{tabular}

Rawal: Migration of Surgical Clips into the Common Bile Duct after Laparoscopic Cholecystectomy

\footnotetext{
5 Onghena T, Vereecken L, Van den Dwey K, Van Loon C: Common bile duct foreign body: an unusual case. Surg Laparosc Endosc 1992;2:8-10.

6 Kitamura K, Yamaguchi T, Nakatani H, Ichikawa D, Shimotsuma M, Yamane T: Why do cystic duct clips migrate into the common bile duct? Lancet 1995;346:965-966.

7 Chong VH, Yim HB, Lim CC: Clip-induced biliary stone. Singapore Med J 2004;45:533-535.

-8 Samim MM, Armstrong CP: Surgical clip found at duodenal ulcer after laparoscopic cholecystectomy: report of a case. Int J Surg 2008;6:473-474.

9 Ammann K, Kiesenbner J, Gadenstatter M, Mathis G, Stoss F: Embolism of a metallic clip: an unusual complication following laparoscopic cholecystectomy. Dig Surg 2000;17:542-544.

10 Anwar S, Rahim R, Agwunobi A, Bancewicz J: The role of ERCP in management of retained bile duct stones after laparoscopic cholecystectomy. N Z Med J 2004;117:1102.

11 Andrews S: Gallstone size related to incidence of post cholecystectomy retained common bile duct stones. Int J Surg 2013;11:319-321.

12 Petelin JB: Laparoscopic common bile duct exploration: lessons learned from $>12$ years experience. Surg Endosc 2003;17:1705-1715.

-13 Ford JA, Soop M, Du J, Loveday BP, Rodgers M: Systematic review of intraoperative cholangiography in cholecystectomy. Br J Surg 2012;99:160-167.

14 Sajid MS, Leaver C, Haider Z, Worthington T, Karanjia N, Singh KK: Routine on-table cholangiography during cholecystectomy: a systematic review. Ann R Coll Surg Engl 2012;94:375-380.
}

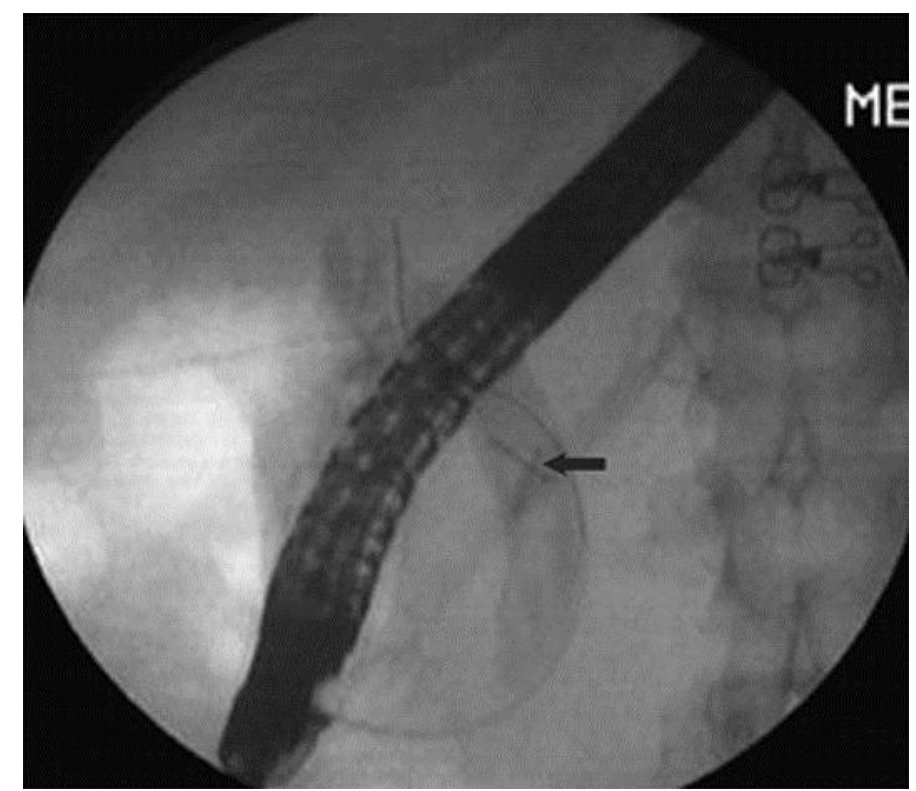

Fig. 1. ERCP image. Two linear metallic densities (arrow) encasing the uppermost filling defect in the CBD. 

www.karger.com/crg

Rawal: Migration of Surgical Clips into the Common Bile Duct after Laparoscopic Cholecystectomy

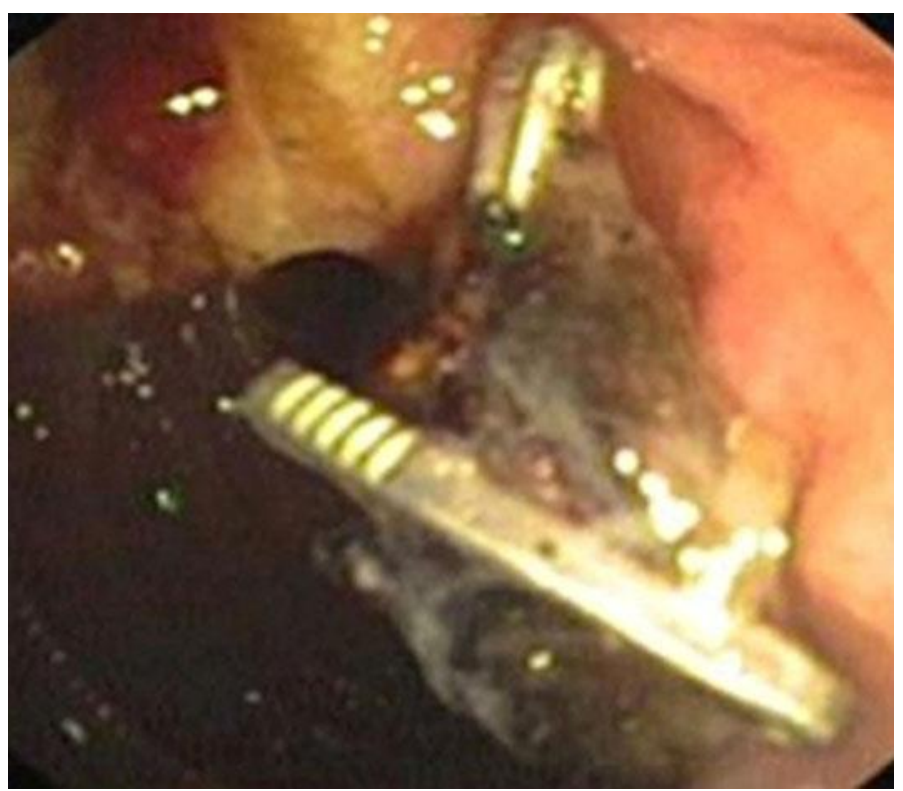

Fig. 2. Endoscopic image. One of the retrieved stones formed over two surgical clips. 